\title{
The Manchester scheme for training overseas psychiatrists
}

\author{
Digby Tantam, Senior Lecturer in Psychiatry, and David Goldberg, Professor of \\ Psychiatry, University Hospital of South Manchester, Manchester
}

There was a time when overseas psychiatrists considered themselves fortunate to come to this country to be an assistant in one of the well-known postgraduate departments. If they showed perseverance they could learn enough to obtain an English postgraduate qualification, and they could participate in the training of English psychiatrists. The more entrepreneurial of them could obtain full-time jobs in psychiatry, but otherwise hands on experience of patient care was limited.

Those days have passed. Countries like Nigeria, many of whose senior psychiatrists spent time at either the Institute of Psychiatry or in Edinburgh, have developed thriving post-graduate training of their own, and are looking critically at the content of training offered here. ${ }^{1}$ There is a much greater awareness that the conditions of psychiatry in the United Kingdom are not essentially the same as those elsewhere. The training needs of psychiatrists intending to practise overseas are likely to be different from those intending to practise in this country. The Membership examination may not be an appropriate test of the acquisition of these different skills. ${ }^{2}$

With the reduction in the number of registrar posts following the implementation of Achieving a Balance, there is likely to be an excess of postgraduate training capacity ${ }^{3}$ which could be used to train overseas psychiatrists. This training will need to attract able trainees from overseas in competition with post-graduate centres in their own countries, in other parts of Europe, and in the United States. Few of these trainees will wish to stay in this country. They will anyway be prohibited from doing so by the Immigration Act of 1985 which requires that medical trainees from outside the European Economic Community obtain a work-permit if they prolong their training beyond four years or if they take up permanent positions. Training will therefore have to be orientated to the needs of their home country.

Two years ago, the Department of Psychiatry in Manchester set up a scheme for training overseas psychiatrists which takes account of these new conditions. It has four components: a full-time, paid training position on one of five rotational schemes in the North-West for which limited registration and exemption from the Professional and Linguistic Assessment Board (PLAB) test is arranged before the trainee arrives; a day-release course in general psychiatry which is attended by other North-West psychiatric trainees; optional registration for the course and supervised research leading to an MSc in Psychiatry; and a special course leading to a new Diploma in Psychiatry awarded by Manchester University. Two other features of the course which are worthy of note are the means of selection of trainees, and the role of the Clinical Tutor to the Scheme (currently DT).

\section{The Diploma in Psychiatry course}

Teaching for the special topics covered by this new Diploma has taken place in evening seminars, and during a special one-week course. The evening seminars have covered delivery of mental health care in primary care settings in developing countries, primary care, child psychiatry, neuropsychiatry, and the organisation of health services. Psychiatrists on the scheme have also been invited to a number of social events in the homes of senior psychiatrists in Manchester to allow more informal discussion.

The comments made in their discussion have influenced the design of the full-time, one-week course on Psychiatry in the Developing World which the Department held in January 1988 which offered intensive teaching to the overseas psychiatrists and others by psychiatrists from all over the country. Topics included teaching methods, training medical students to be primary mental health care providers, organising courses, research techniques and using epidemiological research, evaluation, influencing Government policy, prevention of organic mental disorder, the place of native healers, and the influence of cultural factors on diagnosis and treatment. The course received positive feed-back from the trainees who attended (and one other psychiatrist) although there was a lively debate about whether it was appropriate to slant it to the 'developing' world. Surely English psychiatric services were also 'developing' and could they not learn from the experience of African psychiatrists? 


\section{The selection of trainees}

We have been fortunate in having the support of $\mathrm{Dr}$ John Orley and Dr Norman Sartorius of the World Health Organization in the development of the scheme, and four of the current trainees are in receipt of WHO Fellowships. WHO also assisted us in our first contact with overseas departments of psychiatry.

One of us (DPG) wrote to the Heads of five African departments, and each nominated potential trainees who met our criteria: that they were likely to make a significant contribution to the development of psychiatric services in their home countries in the future, that they were prepared to come to this country for two years, and that they were fluent English speakers. Two other criteria have to be met so that limited registration with exemption from the PLAB can be arranged: the potential trainee has to have spent at least two years in psychiatry, having qualified at least three years before, and his or her primary medical qualification has to be acceptable to the General Medical Council for limited registration. So far this latter condition has debarred applicants from Uganda, from certain medical schools in India and Pakistan, and until recently, from one medical school in Nigeria.

\section{The role of the clinical tutor to the Scheme}

Each trainee on the scheme has contact with two clinical tutors: the clinical tutor for their rotation, and the clinical tutor to the scheme. The former plays much the same role to the trainee on the scheme as to any other trainee on the rotation, and is responsible for allocating the trainee to post. The clinical tutor to the scheme is responsible for organising the training which is specific to the scheme, for selecting trainees for rotations, and for ensuring that their training experience is going to fit them for their likely working conditions in their home countries.

All trainees on the scheme occupy a general psychiatry post on arrival, but many wish to have as much sub-specialty experience as possible, particularly in child psychiatry. In order that all trainees have the greatest range of choice of posts, they have therefore been given the opportunity to move rotations after one year. These transfers have been coordinated by the clinical tutor to the Scheme who has had to consider the practical difficulties over accommodation and transport which the overseas psychiatrist may face.

Smoothing practical difficulties has been one of the aspects of the clinical tutor's job. This is important even before the new trainee's arrival. The trainee will have received a considerable amount of information about the scheme, confirmation of travel and accom- modation arrangements, and advice about immigration regulations before leaving home, plus a letter that they can show to the immigration authorities at the airport in this country. There will also have been previous correspondence with the General Medical Council, and the Overseas Division will have received a curriculum vitae and a completed form LR3, together with a copy of the trainee's original medical qualification and, in the case of trainees from India or Pakistan, a copy of their transcript of studies. The Overseas Division is able, on the basis of these documents, to tell us before the trainee whether or not he or she is eligible for limited registration and their assistance in this respect has been invaluable.

\section{Arrival in the United Kingdom}

It is especially important that the trainees receive assistance in their first few days here, We arrange for someone to meet them at the airport and accompany them whenever possible to their hospital base, where accommodation is organised. They are seen by the clinical tutor on the day of arrival and are orientated to the scheme and to the hospital, introduced to the personnel department from whom a salary advance may be needed, and, if required, to the bank. Few of our trainees stop over in London en route, and the day after arrival usually have to make the journey to London to present the original of their medical certificate and the fee so as to register with the GMC. They also need to join a medical defence society, and usually do that at the same time. The combined fee for these two is massive, and even with an advance and an overdraft is only just manageable. Sterling is not readily available in many African countries, and we are fortunate that a local bank has agreed to provide an immediate overdraft facility for any trainees opening an account with them.

Another important function of the clinical tutor has been to arrange any special teaching requested by trainees. As well as the teaching leading to the Diploma, considered above, this has included teaching in the use of a statistics package on the computer, seminars at the Manchester Business School, and examination coaching.

\section{Future developments}

Over the past two years we have been learning, too. We now know that several African countries have a greater need for sub-speciality training, particularly in child psychiatry, than for general psychiatry training. Although a limited amount of this can be provided on a registrar scheme, there is also the need for training at senior registrar level which our scheme cannot provide and which, as far as we know, is not generally available. 
We have also discovered just how great is the variation in wealth, service development, and psychiatric manpower between countries which we had previously lumped together as 'African countries' or the 'developing world'. These countries have different expectations of what an overseas training can offer, and they have had to be encompassed in the syllabus for the Manchester University Diploma in Psychiatry which our trainees will sit. We hope that this will be seen abroad, not as a weak sister of the Membership examination, but as a new type of qualification, relating to health service administration, evaluation, and the design of services, as well as to general professional expertise.

\section{References}

${ }^{1}$ Cox, J. (1984) Training in psychiatry for developing countries (with special reference to Africa) Bulletin of the Royal College of Psychiatrists, 8, 69-70.

2 _ \& FANUYIWA, O. O. (1984) Attitudes of British and Nigerian teachers to training African psychiatrists in the UK. Bulletin of the Royal College of Psychiatrists, 8, 137-138.

${ }^{3}$ LISTER, J. (1986) The impact of overseas medical graduates on service and training in the United Kingdom. New England Journal of Medicine, 315, 1038-1040.

\section{Trainees forum}

\section{How should you organise an exam workshop?}

\section{An audit and discussion of the usefulness and objectives of a workshop}

\section{S. P. J. LYNCH, Registrar in Psychiatry, Royal Liverpool Hospital, Liverpool}

For several years members of the University Department of Psychiatry and post-membership trainees have organised an informal exam workshop for the final part of the Membership examination of the Royal College of Psychiatrists. This is in addition to existing postgraduate courses in the Region. The workshop concentrates on examination technique rather than on teaching the basic knowledge required. Trainees from within the Mersey Region due to sit the June or November sittings of the final MRCPsych are invited to attend by formal and informal means and the workshop is currently held on a weekly basis over six weeks. According to guidelines laid down by the College ${ }^{1}$, the majority of trainees have access to postgraduate training at a university departmeht of psychiatry; usually by day-release courses. However, these vary widely in their immediate relevance to the Membership examination; and the amount of experience in examination technique. Consequently, several residential preexamination training courses and workshops that give this experience have flourished.

In the Mersey Region, demand amongst trainees for a more informal method of examination practice led to the start of the exam workshop in addition to the established Membership course held on a dayrelease basis at the university. There are possible advantages in having such workshops:

(a) they are more informal settings where deficiencies can be discussed with a peer group in addition to feedback given by examiners; (b) examiners perhaps are more empathic and understand the difficulties as they have only been recently examined themselves!

(c) these offer advantages over study-groups in that the examination situation is more realistically recreated (as all interviews are held in front of fellow candidates) yet there is the informality of having audit by a peer group;

(d) there is the flexibility that emphasis can be quickly changed, e.g. MCQ technique rather than clinical, depending on the needs of candidates.

However, is the experience offered different to that already gained in the Regional Postgraduate Course or other residential courses? It was hoped to assess the validity of these assumptions, i.e. that a different and unique form of experience was available and that this was useful in improving examination technique. Information was also gained about deficiencies in the workshop, and how these could be remedied.

\section{The study}

The workshop is held on Monday from 5.30 p.m. six weeks prior to the Membership examination. The main components are mock clinical and viva but there is flexibility in format with an opportunity to practise and discuss multiple choice type questions (usually in the setting of study groups). Suitable MCQ papers have been provided by the Department to study in previous examination workshops.

There were up to nine examiners available to 